\title{
VALUASI EKONOMI SUMBERDAYA HUTAN MANGROVE DI DESA PALAES KECAMATAN LIKUPANG BARAT KABUPATEN MINAHASA UTARA
}

\author{
Benu Olfie L. Suzana \\ Jean Timban \\ Rine Kaunang \\ Fandi Ahmad
}

\begin{abstract}
The purpose of this study to determine the economics value of mangrove forest ecosystems, as well as its contribution to society in the region of mangrove research sites in the Palaes Village, District of West Likupang, North Minahasa regency. In this research, using primary and secondary data. The variables measured were the direct benefit of the value generated from direct utilization of mangrove forests such as the potential for wood (timber and firewood), palm leaves craftsmen, catching fish, shrimp and crab (Rp/year). The value of benefits Indirect value resulting from the utilization of mangrove forest indirectly named as breaking waves (break water) (Rp/year). Value of benefit options, namely the economic value derived from potential direct or indirect utilization of a resource / ecosystem in the future the value of Biodiversity (Rp/year).

Based on INP calculation to determine the existence of a species in a community under study, obtained Palaes Village mangrove forest dominated by Rhizophora at 109,499. INP data from other species in a row on the kind of Brugiera of 58,088, amounting to 57,492 Ceriops species, Xilocarpus of 41,491, 20,860 species of Sonneratia and Avicennia species amounted to 12,860 .

Based on the calculations found that the benefits obtained if mangrove forests are maintained at Rp10,888,218,123,/year, calculated from the sum of the direct benefits other than timber potential, indirect benefits and benefits options. Meanwhile, if the potential for exploitation of timber obtained a profit of Rp273,617,273/year. It can be concluded that if the mangrove forest is maintained, then the benefits will 39.8 times greater than exploiting the natural resources of mangrove forests Palaes Village.

By considering the total economic value derived from the mangrove forest ecosystem in Palaes Village, it has the benefits of mangrove forest and an important functions as economic resources and ecological resources for the life of the people who are around him. Therefore, the presence of (physical condition) of mangrove forest ecosystems must be maintained as an asset development, be it by local communities and other parties such as government, private sector, researchers and LSM, so that development activities can work well and the availability of mangrove forest resources remain secure.
\end{abstract}

Keywords: Mangrove Forest Palaes Village, Important value index, Economics Value, Cost

\section{PENDAHULUAN}

\section{Latar Belakang}

Sumberdaya alam mempunyai peran penting dalam kelangsungan hidup manusia. Pengelolaan terhadap sumberdaya alam harus sangat bijaksana. Karena diperlukan waktu yang cukup lama untuk bisa memulihkan kembali apabila telah terjadi kerusakan/kepunahan. Pengelolaan secara bijaksana yaitu pemanfaatan dan pengelolaan sumberdaya yang optimal dan berwawasan lingkungan agar sumberdaya alam yang ada tetap lestari.

Ekosistem hutan mangrove merupakan salah satu sumberdaya alam wilayah pesisir yang mempunyai peranan penting ditinjau dari sudut sosial, ekonomi, dan ekologis. Fungsi utama sebagai penyeimbang ekosistem dan penyedia berbagai kebutuhan hidup bagi manusia dan mahluk hidup lain- 
nya. Sumberdaya hutan mangrove, selain dikenal memiliki potensi ekonomi sebagai penyedia sumberdaya kayu juga sebagi tempat pemijahan (spawning ground), daerah asuhan (nursery ground), dan juga sebagai daerah untuk mencari makan (feeding ground) bagi ikan dan biota laut lainnya, juga berfungsi untuk menahan gelombang laut dan intrusi air laut kearah darat

Besarnya manfaat yang ada pada ekosistem hutan mangrove, memberikan konsekuensi bagi ekosistem hutan mangrove itu sendiri, yaitu dengan semakin tingginya tingkat eksploitasi terhadap lingkungan yang tidak jarang berakhir pada degradasi lingkungan yang cukup parah.

Sebagai contoh adalah berkurangnya luasan hutan mangrove dari tahun ke tahun. Hal ini tidak terlepas dari ulah manusia yang kurang paham akan pentingnya kelestarian ekosistem hutan mangrove di kemudian hari. Masyarakat hanya menilai hutan mangrove dari segi ekonominya saja, tanpa memperhatikan manfaat-manfaat fisik dan juga biologi yang ditimbulkan.

\section{Perumusan masalah}

Berdasarkan latar belakang diatas, yang menjadi permasalahan penelitian ini adalah berapa besar harga/nilai kuantitatif ekosistem hutan mangrove agar diketahui berapa harga/nilai kuantitatif yang akan hilang dan akibat yang akan dialami oleh manusia jika ekosistem hutan mangrove tidak dikelola dengan bijaksana.

\section{Tujuan Penelitian}

Penelitian ini bertujuan untuk melakukan penilaian ekonomi terhadap ekosistem hutan mangrove, serta kontribusinya terhadap masyarakat di wilayah lokasi penelitian mangrove di Desa Palaes, Kecamatan Likupang Barat, Kabupaten Minahasa Utara.

\section{Manfaat Penelitian}

Penelitian ini diharapkan dapat dijadikan sebagai bahan masukan bagi para pengambil kebijakan dalam perencanaan dan pengelolaan sumberdaya hutan mangrove.

\section{METODE PENELITIAN}

\section{Waktu dan Tempat Penelitian}

Penelitian ini dilakukan di Desa Palaes Kecamatan Likupang Barat Kabupaten Minahasa Utara, yang dilaksanakan pada bulan Juli - Oktober 2010 .

\section{Metode Pengambilan Sampel}

Metode pengambilan sampel dalam penelitian ini adalah dengan menggunakan metode Purposive Sampling. Sampel petani yang akan di wawancarai adalah sebanyak 30 responden.

\section{Konsep Pengukuran Variabel}

Variabel yang akan diukur dalam penelitian ini adalah:

1. Nilai manfaat langsung yaitu nilai yang dihasilkan dari pemanfaatan secara langsung hutan mangrove: potensi kayu (kayu bangunan dan kayu bakar), pengrajin daun nipah, penangkapan ikan, udang dan kepiting (Rp/tahun).

2. Nilai manfaat tidak langsung yaitu nilai yang dihasilkan dari pemanfaatan secara tidak langsung hutan mangrove: pemecah ombak (break water) (Rp/tahun)

3. Nilai manfaat pilihan yaitu nilai ekonomi yang diperoleh dari potensi pemanfaatan langsung maupun tidak langsung dari sebuah sumberdaya/ekosistem di masa datang: nilai Biodiversity (Rp/tahun).

4. Biaya yaitu biaya yang dikeluarkan oleh pemanfaat hutan mangrove untuk mendapatkan komoditi dari hutan mangrove (Rp/tahun).

\section{Masyarakat}

\section{Metode Pengumpulan Data}

Masyarakat yang dijadikan responden adalah beberapa pemanfaat hutan mangrove, antara lain : nelayan, pencari kayu bakar, pengrajin daun nipah, dan juga pada masyarakat yang berhubungan dengan mangrove secara tidak langsung. Untuk mengetahui keadaan umum lokasi penelitian dan kondisi hutan mangrove yang ada, juga dilakukan wawancara dengan aparat desa, petugas kehutanan setempat, dan juga warga desa. 


\section{Vegetasi}

Pengambilan contoh untuk analisis vegetasi dilakukan dengan menggunakan transek garis (line transec). Tahapan dalam mengambil data transek yaitu menarik meteran ke arah laut dengan posisi awal yang telah diberi tanda (patok atau pengecatan pohon dan menentukan blok (petak contoh/petak ukur) di sebelah kiri dan kanan garis transek berbentuk bujursangkar dengan ukuran 10 x $10 \mathrm{~m}$ untuk pengamatan fase pohon.

\section{Metode Pengolahan dan Analisis Data} Analisis Volume Tegakan

Analisis volume tegakan dilakukan untuk mengetahui besar dari volume kayu mangrove yang ada. Untuk mendapatkan volume kayu, maka harus diketahui terlebih dahulu nilai dari tinggi dan juga keliling lingkaran setinggi dada $(1,3 \mathrm{~m})$ pohon yang menjadi sampel. Data yang diperoleh dimasukkan dalam Tabel 1.

Tabel 1. Perhitungan Volume Kayu Mangrove

\begin{tabular}{|l|l|l|l|l|}
\hline No. & $\begin{array}{c}\text { Jenis } \\
\text { mangrove }\end{array}$ & $\begin{array}{c}\text { Diameter } \\
(\mathrm{cm})\end{array}$ & $\begin{array}{c}\text { Tinggi } \\
(\mathrm{m})\end{array}$ & $\begin{array}{c}\text { Volume } \\
\text { kayu } \\
\left(\mathrm{m}^{3}\right)\end{array}$ \\
\hline 1. & & & & \\
\hline 2. & & & & \\
\hline
\end{tabular}

Dalam Santoso (2005) volume kayu mangrove ini didapat dengan menggunakan persamaan:

$\mathrm{V}=(\operatorname{Lbd} \times \mathrm{t})$

Dimana:

$\mathrm{V}=$ Volume

Lbd = luas bidang dasar $\{[($ diameter/100) $\times 0.5]$ $\left.{ }^{2}\right\} \times 3.14$

$\mathrm{T} \quad=$ tinggi $(\mathrm{m})$

$\Pi=3,14$

Analisis volume tegakan yang didapat ini akan menggambarkan kondisi dari hutan mangrove pada tiap hektar. Selain itu juga dapat dijadikan perhitungan awal dari nilai ekonomi potensi kayu mangrove.

Nilai tegakan dapat diketahui dengan menghitung kubikasi kayu yang dihasilkan, dikalikan dengan harga jual tiap $\mathrm{m}^{3}$ dikalikan dengan luasan kemudian dikurangi dengan biaya operasional.

\section{Indeks Nilai Penting}

Kondisi ekologis hutan mangrove dapat diketahui dengan menggunakan beberapa jenis perhitungan, yaitu kerapatan jenis, frekuensi jenis, luas area penutupan, dan Indeks Nilai Penting (INP) dari tiap jenis. Untuk mencari nilai INP digunakan tiga perhitungan, yaitu nilai kerapatan tiap jenis, nilai frekuensi tiap jenis, dan nilai dari penutupan tiap jenis.

Kerapatan jenis (Di) adalah jumlah tegakan jenis i dalam suatu area. Persamaan untuk mencari kerapatan jenis adalah:

$\mathrm{Di}=\mathrm{ni} / \mathrm{A} \ldots \ldots \ldots \ldots \ldots \ldots \ldots 2)$

\section{Dimana:}

$\mathrm{Di}=$ Kerapatan jenis ke $-\mathrm{i}$

$\mathrm{ni}=$ Jumlah total tegakan dari jenis ke $-\mathrm{i}$

$\mathrm{A}=$ Luas total area pengambilan contoh

Setelah nilai dari kerapatan jenis ini didapat, langkah selanjutnya adalah mencari nilai dari kerapatan relatif jenis (RDi). Kerapatan relatif jenis adalah perbandingan antara jumlah tegakan jenis i (ni) dan jumlah total tegakan seluruh jenis $\left(\sum \mathrm{n}\right)$, dengan persamaan:

$$
\mathrm{RDi}=\left(\mathrm{ni} / \sum \mathrm{n}\right) \times 100
$$

Penutupan jenis (Ci) adalah luas penutupan jenis i dalam suatu area. Persamaan dari penutupan jenis adalah:

$$
\mathrm{Ci}=\sum \mathrm{BA} / \mathrm{A}
$$

\section{Dimana:}

$$
\mathrm{BA}=\pi \mathrm{DBH} 2 / \mathrm{A} ;(\pi=3,14)
$$

$\mathrm{DBH}=$ diameter batang pohon jenis $\mathrm{ke}-\mathrm{i}$

$\mathrm{DBH}=\mathrm{CBH} / \pi ; \mathrm{CBH}$ adalah lingkar pohon setinggi dada

A $=$ luas total area pengambilan contoh

Setelah nilai dari penutupan jenis ini didapat, langkah selanjutnya adalah mencari nilai dari 
penutupan relatif jenis (RCi). Nilai penutupan relatif jenis adalah perbandingan antara luas area penutupan jenis i (Ci) dan luas total area penutupan untuk seluruh jenis $\left(\sum \mathrm{C}\right)$, dengan persamaan:

$$
\left.\mathrm{RCi}=\left(\mathrm{Ci} / \sum \mathrm{C}\right) \times 100 \ldots \ldots \ldots \ldots \ldots . \ldots 5\right)
$$

Nilai yang terakhir yaitu nilai frekuensi tiap jenis. Frekuensi jenis sendiri merupakan peluang ditemukannya jenis i dalam petak contoh / plot yang diamati:

$\mathrm{Fi}=\mathrm{Pi} / \sum \mathrm{P}$

Dimana, Fi adalah frekuensi jenis i, Pi adalah jumlah petak contoh / plot dimana ditemukan jenis i. Sedangkan P adalah jumlah total petak contoh/ plot. Setelah nilainya didapat, selanjutnya adalah menghitung nilai frekuensi relatif jenis yang merupakan perbandingan antara frekuensi jenis $i$ (Fi) dan jumlah frekuensi untuk seluruh jenis $\left(\sum \mathrm{F}\right)$ :

$\left.\mathrm{RFi}=\left(\mathrm{Fi} / \sum \mathrm{F}\right) \times 100\right)$

Indeks nilai penting adalah jumlah nilai kerapatan jenis (RDi), frekuensi relatif jenis (RFi), dan penutupan relatif jenis (RCi).

$\mathrm{INP}=\mathrm{RDi}+\mathrm{RFi}+\mathrm{RCi}$.

Nilai penting ini untuk memberikan suatu gambaran mengenai pengaruh atau peranan suatu jenis mangrove dalam ekosistem tersebut. Indeks nilai penting memiliki kisaran antara 0-300.

\section{Valuasi Ekonomi Hutan Mangrove}

Penilaian ekonomi sumberdaya mangrove dilakukan dengan menggunakan dua tahap pendekatan:

1. Identifikasi manfaat dan fungsi-fungsi sumberdaya hutan mangrove.

2. Kuantifikasi seluruh manfaat dan fungsi ke dalam nilai uang.

\section{Identifikasi Manfaat dan Fungsi yang terkait dengan Hutan Mangrove}

Nilai ekonomi suatu sumberdaya hutan mangrove dibagi menjadi nilai penggunaan dan nilai non penggunaan. Nilai penggunaan dibagi menjadi dua, yaitu nilai langsung dan nilai tidak langsung. Nilai non penggunaan dibagi menjadi tiga, yang meliputi nilai manfaat pilihan, nilai manfat keberadaan, dan manfaat pewarisan.

1. Nilai manfaat langsung (direct use value)

Nilai manfaat langsung adalah nilai yang dihasilkan dari pemanfaatan secara langsung dari suatu sumberdaya. Manfaat langsung bisa diartikan manfaat yang dapat dikonsumsi. Nilai manfaat langsung hutan mangrove dihitung dengan persamaan:

$\mathrm{DUV}=\sum$ DUVi $\ldots \ldots \ldots \ldots \ldots \ldots$ )

Dimana:

DUV = Direct use value

DUV 1 = manfaat kayu

DUV 2 = manfaat penangkapan ikan

DUV 3 = manfaat pengambilan daun nipah

DUV 4 = manfaat penangkapan kepiting

2. Nilai manfaat tidak langsung (indirect use value)

Manfaat tidak langsung adalah nilai manfaat dari suatu sumberdaya (mangrove) yang dimanfaatkan secara tidak langsung oleh masyarakat. Manfaat tidak langsung hutan mangrove dapat berupa manfaat fisik yaitu sebagai penahan abrasi air laut.

Penilaian hutan mangrove secara fisik dapat diestimasi dengan fungsi hutan mangrove sebagai penahan abrasi.

\section{Manfaat pilihan (option value)}

Manfaat pilihan untuk hutan mangrove biasanya menggunakan metode benefit transfer, yaitu dengan cara menilai perkiraan benefit dari tempat lain (dimana sumberdaya tersedia) lalu benefit tersebut ditransfer untuk memperoleh perkiraan yang kasar mengenai manfaat dari lingkungan. Metode tersebut didekati dengan cara menghitung besarnya nilai keanekaragaman hayati yang ada pada ekosistem mangrove tersebut. Menurut Rui- 
tenbeek (1991) dalam Fahrudin (1996), hutan mangrove Indonesia mempunyai nilai biodiversity sebesar US\$1,500 per $\mathrm{km}^{2}$. Nilai ini dapat dipakai di seluruh hutan mangrove yang ada di Indonesia apabila ekosistem hutan mangrovenya secara ekologis penting dan tetap dipelihara secara alami. Nilai manfaat pilihan ini diperoleh dengan persamaan:

$\mathrm{OV}=\mathrm{US} \$ 15$ per ha $\mathrm{x}$ luas hutan mangrove .... .9)

Dimana: $\mathrm{OV}=$ option value

\section{Kuantifikasi Manfaat ke dalam Nilai Uang}

Setelah seluruh manfaat dapat diidentifikasi, selanjutnya adalah mengkuantifikasi seluruh manfaat ke dalam nilai uang dengan beberapa nilai yaitu:

1. Nilai pasar

Pendekatan nilai pasar ini digunakan untuk menghitung nilai ekonomi dari komoditaskomoditas yang langsung dapat dimanfaatkan dari sumberdaya mangrove.

2. Harga tidak langsung

Pendekatan ini digunakan untuk menilai manfaat tidak langsung dari hutan mangrove.

3. Contingent value method

Pendekatan CVM digunakan untuk menghitung nilai dari suatu sumberdaya yang tidak dijual di pasaran, contohnya nilai keberadaan.

4. Nilai manfaat ekonomi total

Nilai manfaat total dari hutan mangrove merupakan penjumlahan seluruh nilai ekonomi dari manfaat hutan mangrove yang telah diidentifikasi dan dikuantifikasikan. Nilai manfaat total tersebut menggunakan persamaan:

$$
\mathrm{TEV}=\mathrm{DV}+\mathrm{IV}+\mathrm{OV}+\mathrm{EV} .
$$

\section{Dimana:}

$\mathrm{TEV}=$ Total economic value

DV = Nilai manfaat langsung

IV = Nilai manfaat tidak langsung

$\mathrm{OV}=$ Nilai manfaat pilihan

$\mathrm{EV}=$ Nilai manfaat keberadaan

\section{HASIL DAN PEMBAHASAN}

\section{Keadaan Umum Wilayah}

Data mengenai keadaan umum wilayah Desa Palaes Kecamatan Likupang Barat Kabupaten Minahasa Utara merupakan data sekunder yang bersumber dari data monografi desa.

\section{Letak Administratif}

Desa Palaes secara administratif berada di Kecamatan Likupang Barat Kabupaten Minahasa Utara. Desa Palaes yang merupakan lokasi penelitian adalah salah satu desa pesisir yang berbatasan langsung dengan Laut Sulawesi. Desa ini memiliki luas 4.116 ha dan mempunyai batas administratif desa sebagai berikut:

Sebelah Utara : Laut Sulawesi dan Desa Maliambao

Sebelah Selatan: Desa Batu dan Desa Kasuratan Sebelah Barat : Desa Kulu dan Desa Lantung Sebelah Timur : Desa Werot

\section{Kependudukan}

Penduduk Desa Palaes berjumlah 1.115 jiwa dengan luas wilayah 4.116 ha, dimana penduduk yang berjenis kelamin laki-laki berjumlah 577 jiwa dan penduduk yang berjenis kelamin perempuan berjumlah 578 jiwa.

Masyarakat yang tinggal di Desa Palaes berasal dari Suku Minahasa, Suku Nusa Utara dan Suku Garontalo/Atinggola,

\section{Tingkat Pendidikan}

Tingkat pendidikan masyarakat Desa Palaes dari total penduduk sebanyak 1.115 jiwa adalah 12 orang berpendidikan sarjana, 272 orang berpendidikan SLTA, 347 orang berpendidikan SLTP, 362 orang berpendidikan SD.

Jumlah sarana dan prasarana sekolah yang ada di Desa Palaes masih sedikit. Di desa ini terdapat 1 bangunan Taman Kanak - Kanak (TK), 2 bangunan Sekolah Dasar (SD), dan 1 bangunan Sekolah Lanjutan Tingkat Pertama (SLTP).

\section{Mata Pencaharian}

Pekerjaan pada sektor perkebunan dan perikanan masih mendominasi masyarakat di Desa Palaes. Hal ini dikarenakan luas wilayah yang ada di 
Desa Palaes sebagian besar merupakan area perkebunan, selain itu letak desa yang berbatasan langsung dengan Laut Celebes memberikan peluang bagi masyarakat untuk berprofesi sebagai nelayan. Untuk lebih jelasnya dapat dilihat pada Tabel 2.

Tabel 2. Jumlah Penduduk Berdasarkan Mata Pencaharian di Desa Palaes

\begin{tabular}{|l|l|c|c|}
\hline No & $\begin{array}{c}\text { Jenis Peker- } \\
\text { jaan }\end{array}$ & $\begin{array}{c}\text { Jumlah Pendu- } \\
\text { duk (jiwa) }\end{array}$ & $\%$ \\
\hline 1 & Petani & 308 & 75.12 \\
\hline 2 & Nelayan & 37 & 9.02 \\
\hline 3 & Pedagang & 32 & 7.8 \\
\hline 4 & PNS & 15 & 3.7 \\
\hline 5 & $\begin{array}{l}\text { Pegawai } \\
\text { Swasta }\end{array}$ & 18 & 4.4 \\
\hline & Jumlah & 410 & 100 \\
\hline
\end{tabular}

Sumber: Data monografi desa

\section{Pengelolaan Hutan Mangrove}

Hutan mangrove yang menjadi objek penelitian adalah hutan mangrove yang terdapat di Desa Palaes yang luasnya mencapai $307 \mathrm{Ha}$. Selama ini hutan mangrove yang ada hanya dibiarkan saja tanpa adanya pengelolaan.

\section{Kondisi Hutan Mangrove}

Kondisi hutan mangrove di Desa palaes relatif cukup baik, hal ini dikarenakan masyarakat Desa Palaes sangat menjaga keberadaan hutan mangrove. Hal ini ditunjukkan dengan dimasukkannya pelestarian mangrove ke dalam peraturan desa. Masyarakat Desa Palaes sudah paham mengenai fungsi dan dampak yang akan mereka alami jika hutan mangrove di desa mereka mengalami kerusakan.

Ancaman kerusakan hutan mangrove datang dari pihak luar, yakni adanya beberapa orang yang bukan merupakan warga setempat yang melakukan pencurian kayu mangrove untuk dijual sebagai kayu bakar.

\section{Analisis Volume Tegakan}

Analisis volume tegakan digunakan untuk mencari tahu berapa besar dari volume yang dapat dihasilkan kayu mangrove dalam tiap hektarnya. Data ini dapat digunakan untuk mencari nilai manfaat langsung hutan mangrove dilihat berdasarkan potensi kayu yang dapat dihasilkan.

Dari hasil pengambilan data diameter batang kayu dan juga tinggi pohon mangrove diperoleh hasil potensi volume kayu mangrove sebesar 49.5 $\mathrm{m}^{3}$ per ha.

\section{Indeks Nilai Penting Pohon Mangrove}

Berdasarkan hasil identifikasi dan pengamatan lapangan terhadap mangrove yang tumbuh di Desa Palaes ditemukan 6 jenis vegetasi mangrove antara lain Lolaro (Rhizophora spp), Kayu ting (Ceriops tagal), makurung (Brugiera gymnorrhiza), kirakira hitam (Xylocarpus spp ), posi-posi (Sonneratia caseolaris) dan api-api (Avecennia spp). Adapun hasil analisis vegetasi dapat dilihat pada Tabel 3.

\section{Potensi Kayu}

Hutan mangrove di Desa Palaes memiliki luasan mencapai 307 hektar. Berdasarkan hasil inventarisasi, potensi kayu komersial yang terdapat pada hutan mangrove di Desa Palaes adalah $15.200,96 \mathrm{~m}^{3}$, sehingga nilai manfaat bersih kayu mangrove diperoleh sebesar Rp6.840.431.843. Nilai ini didapat dari perkalian antara potensi kayu dengan harga tiap meter kubik kayu mangrove sebesar Rp800.000 dan dikurangi dengan biaya pemanfaatan sebesar Rp350.000 per meter kubik. Dengan asumsi siklus tebang 25 tahun maka dengan metode produktifitas didapat nilai nilai potensi kayu hutan mangrove Desa Palaes adalah sebesar Rp273.617.273 per tahun.

Pada Tabel 3 terlihat bahwa hutan mangrove yang ada di Desa Palaes didominasi oleh jenis Lolaro (Rhizophora spp), yang ditunjukkan dengan nilai INP yaitu sebesar 109.5 dan secara berturutturut Bruguiera gymnorrhiza $(58,088)$, Ceriops tagal $(57,492)$, Xylocarpus spp $(41,491)$, Sonneratia caseolaris $(20,570)$ dan Avecennia spp $(12,860)$. 
Tabel 3. Indeks Nilai Penting Jenis Pohon Mangrove di Desa Palaes

\begin{tabular}{|l|l|r|r|r|r|}
\hline No. & \multicolumn{1}{|c|}{ Jenis Mangrove } & $\begin{array}{c}\text { Kerapatan Re- } \\
\text { latif Jenis }\end{array}$ & $\begin{array}{c}\text { Frekuensi } \\
\text { Relatif Jenis }\end{array}$ & $\begin{array}{c}\text { Penutupan Re- } \\
\text { latif Jenis }\end{array}$ & $\begin{array}{c}\text { Indeks Nilai } \\
\text { Penting }\end{array}$ \\
\hline 1 & Rhizophora spp & 35.106 & 23.810 & 50.583 & 109.499 \\
\hline 2 & Bruguiera gymnorrhiza & 14.362 & 16.667 & 27.060 & 58.088 \\
\hline 3 & Ceriops tagal & 23.936 & 23.810 & 9.746 & 57.492 \\
\hline 4 & Xylocarpus spp & 13.830 & 19.048 & 8.614 & 41.491 \\
\hline 5 & Sonneratia caseolaris & 7.979 & 9.524 & 3.067 & 20.570 \\
\hline 6 & Avecennia spp & 4.787 & 7.143 & 0.930 & 12.860 \\
\hline
\end{tabular}

Sumber: Data primer setelah diolah, 2010

\section{Kuantifikasi Manfaat Hutan Mangrove Desa Palaes}

\section{Manfaat Langsung}

Berdasarkan hasil identifikasi, manfaat hutan mangrove yang dapat langsung dikonsumsi mencakup manfaat hasil hutan kayu, manfaat penangkapan hasil perikanan, serta manfaat pengambilan daun nipah.

Tabel 4. Nilai Manfaat Kayu Komersil pada Ekosistem Hutan Mangrove Desa Palaes

\begin{tabular}{|l|l|l|}
\hline No. & \multicolumn{1}{|c|}{ Uraian } & \multicolumn{1}{c|}{ Jumlah } \\
\hline 1 & $\begin{array}{l}\text { Luas Hutan Man- } \\
\text { grove }\end{array}$ & 307 hektar \\
\hline 2 & $\begin{array}{l}\text { Potensi Kayu Ko- } \\
\text { mersil }\end{array}$ & $15.200,96 \mathrm{~m}^{3}$ \\
\hline 3 & Harga Kayu & $\mathrm{Rp} 800.000 / \mathrm{m}^{3}$ \\
\hline 4 & $\begin{array}{l}\text { Nilai Kotor Manfaat } \\
\text { Kayu Mangrove }\end{array}$ & $\mathrm{Rp} 12.160 .767 .721$ \\
\hline 5 & $\begin{array}{l}\text { Biaya Pemanfaatan } \\
\text { (tebang \& angkut })\end{array}$ & $\mathrm{Rp} 350.000 / \mathrm{m}^{3}$ \\
\hline 6 & Total Biaya & $\mathrm{Rp} 5.320 .335877$ \\
\hline 7 & $\begin{array}{l}\text { Nilai Bersih Manfaat } \\
\text { Kayu Mangrove }\end{array}$ & $\mathrm{Rp} 6.840 .431 .843$ \\
\hline 8 & $\begin{array}{l}\text { Nilai potensi kayu } \\
\text { per tahun }\end{array}$ & $\mathrm{Rp} 273.617 .273$ \\
\hline
\end{tabular}

Sumber: Data primer setelah diolah 2010

Perlu digarisbawahi bahwa nilai kayu disini merupakan nilai kesempatan dari keseluruhan aliran manfaat yang diberikan oleh hutan mangrove.
Hal ini berarti bahwa apabila dilakukan eksploitasi terhadap kayu yang ada maka manfaat lain dari hutan mangrove akan berkurang atau bahkan hilang.

\section{Potensi Kayu Bakar}

Pengambilan kayu bakar dilakukan oleh masyarakat adalah kayu-kayu kering yang terdapat pada hutan mangrove dan dijual dengan harga Rp1.250 per ikat. Dalam setahun kayu bakar yang dihasilkan mangrove dapat mencapai 180 ikat. Nilai manfaat kayu bakar didapat dengan cara mengalikan harga jual kayu per ikat dengan banyaknya kayu bakar yang dihasilkan, sehingga didapat nilai sebesar Rp225.000 per tahun.

\section{Penangkapan Ikan, Udang dan Kepiting}

Penangkapan ikan dilakukan dengan menggunakan alat berupa pancing dan jaring (zero). Nilai manfaat penangkapan ikan mencapai Rp146.400.000 per tahun. Nilai ini didapat dari hasil penjualan ikan sebesar Rp20.000 per kg yang kemudian dikalikan dengan hasil rata-rata ikan yaitu sebesar $7.320 \mathrm{~kg}$. Biaya yang digunakan mencapai Rp28.140.000 per tahun. Dengan demikian nilai manfaat bersih yang dihasilkan sebesar Rp118.260.000 per tahun.

Selain ikan, manfaat yang kedua adalah penangkapan kepiting. Manfaat penangkapan kepiting diperoleh sebesar Rp45.000.000 per tahun. Nilai ini didapat dengan cara mengalikan hasil penangkapan kepiting per tahun yaitu sebanyak 900 
$\mathrm{kg}$ dengan harga jual rata-rata yaitu sebesar Rp50.000 . Biaya yang dikeluarkan mencapai Rp1.800.000 per tahun. Sehingga manfaat bersih yang diperoleh dari penangkapan kepiting ini sebesar Rp43.200.000 per tahun.

Manfaat yang ketiga yaitu penangkapan udang windu. Manfaat penangkapan udang windu diperoleh sebesar Rp16.200.000 per tahun. Nilai ini didapat dengan cara mengalikan hasil penangkapan udang windu per tahun yaitu sebanyak 324 ekor dengan harga jual rata-rata yaitu sebesar Rp50.000 . Biaya pemanfaatan yang dikeluarkan mencapai Rp2.592.000 per tahun. Sehingga manfaat bersih yang diperoleh dari penangkapan udang windu ini sebesar Rp13.608.000 per tahun.

\section{Pengambilan Daun Nipah}

Jenis pemanfaatan yang terakhir adalah pengambilan daun nipah untuk dijadikan atap rumah (woka). Jumlah daun nipah yang dihasilkan mencapai 9600 lembar/tahun. Jumlah Nilai manfaat ini didapat dari hasil penjualan atap dari daun nipah seharga Rp1.500 per lembar. Biaya yang dikeluarkan untuk pembuatan atap dari daun nipah sebesar Rp4.800.000 per tahun. Maka nilai manfaat bersih yang diperoleh sebesar Rp9.600.000 per tahun.

\section{Manfaat Tidak Langsung}

Manfaat tidak langsung dari hutan mangrove sebagai penahan abrasi disetimasi melalui replacement cost dengan pembangunan bangunan pemecah gelombang (break water). Menurut data Dinas Pekerjaan Umum Propinsi Sulawesi Utara (2009) untuk membuat bangunan pemecah gelombang dengan ukuran $37,5 \mathrm{~m}$ x $2 \mathrm{~m}$ x 2,5 $\mathrm{m}$ (p x 1 x t) dengan daya tahan 5 tahun diperlukan biaya sebesar Rp265.727.775 atau sekitar Rp.7.086.074 per meter. Panjang garis pantai yang dilindungi hutan mangrove yaitu 7.530 meter. Nilai dari biaya pembuatan breakwater tersebut kemudian dikalikan dengan panjang garis pantai yang terlindungi hutan mangrove, yaitu sepanjang 7.530 meter. Hal ini dikarenakan bangunan pemecah ombak tersebut sudah dapat menggantikan fungsi dari hutan mangrove sebagai pemecah gelombang pada sepanjang garis pantai Desa Palaes, sehingga manfaat tidak langsung mangrove sebagai penahan ab- rasi adalah sebesar Rp53.358.137.418 Nilai tersebut kemudian dibagi 5 guna mendapatkan nilai per tahunnya. Dengan demikian manfaatnya adalah sebesar Rp10.671.627.483 per tahun.

\section{Manfaat Pilihan}

Manfaat pilihan pada ekosistem hutan mangrove yang ada di Desa Palaes dapat didekati dengan menggunakan metode benefit transfer, yaitu dengan cara menilai perkiraan benefit dari tempat lain (dimana sumberdaya tersedia) kemudian benefit tersebut di transfer untuk memperoleh perkiraan yang kasar mengenai manfaat dari lingkungan. Metode tersebut didekati dengan cara menghitung dari manfaat keanekaragaman hayati (biodiversity) yang ada pada kawasan mangrove ini. Menurut Ruitenbeek (1991) dalam Fahrudin (1996) hutan mangrove Indonesia mempunyai nilai biodiversity sebesar US\$1,500 per $\mathrm{km}^{2}$ atau US\$15 per ha per tahunnya. Nilai ini dapat dipakai diseluruh hutan mangrove yang ada di seluruh wilayah Indonesia apabila ekosistem hutan mangrovenya secara ekologis penting dan tetap terpelihara secara alami. Nilai total dari manfaat biodiversity ini didapat dengan cara mengalikan nilai manfaatnya yaitu US\$15 per ha per tahun dengan nilai tukar rupiah terhadap dolar AS yaitu Rp8.968 (pada 15 Oktober 2010), sehingga didapat nilai sebesar Rp134.520 . Hasil tersebut dikalikan dengan luas total dari ekosistem hutan mangrove yang ada saat ini yaitu seluas $307 \mathrm{Ha}$. Dengan demikian nilai total dari manfaat biodiversity pada hutan mengrove di Desa Palaes sebesar Rp41.297.640 per tahun.

\section{Nilai Manfaat Total Hutan Mangrove}

Nilai manfaat total dari hutan mangrove merupakan penjumlahan dari manfaat-manfaat hutan mangrove yang telah diidentifikasi dan dikuantifikasi selain manfaat potensi kayu. Proporsi manfaat total dari hutan mangrove Desa Palaes tampak pada Tabel 5. 
Tabel 5. Nilai Manfaat Total dari Hutan Mangrove Desa Palaes

\begin{tabular}{|c|l|c|c|}
\hline No. & $\begin{array}{l}\text { Jenis Man- } \\
\text { faat }\end{array}$ & $\begin{array}{c}\text { Nilai Manfaat } \\
\text { (Rp/tahun) }\end{array}$ & $\mathbf{( \% )}$ \\
\hline 1 & $\begin{array}{l}\text { Manfaat } \\
\text { langsung }\end{array}$ & 175.293 .000 & 1,61 \\
\hline 2 & $\begin{array}{l}\text { Manfaat ti- } \\
\text { dak lang- } \\
\text { sung }\end{array}$ & 10.671 .627 .483 & 97,99 \\
\hline 3 & $\begin{array}{l}\text { Manfaat pi- } \\
\text { lihan }\end{array}$ & 41.297 .640 & 0,40 \\
\hline Nilai Manfaat Total & 10.888 .218 .123 & 100 \\
\hline
\end{tabular}

Sumber: Data primer setelah diolah 2010

\section{KESIMPULAN DAN SARAN}

\section{Kesimpulan}

1. Berdasarkan hasil penelitian diperoleh nilai ekonomi total hutan mangrove di Desa Palaes sebesar Rp10.888.218.123 per tahun, yang dihitung dari manfaat langsung (Rp175.293.000 per tahun), manfaat tidak langsung (Rp10.671.627.483 per tahun) dan manfaat pilihan (Rp.41.297.640 per tahun).

2. Jika potensi kayu di eksploitasi didapat keuntungan sebesar Rp273.617.273 per tahun. Dapat disimpulkan bahwa jika hutan mangrove dipertahankan, maka keuntungan akan 39.8 kali lebih besar dibandingkan mengeksploitasi sumberdaya alam hutan mangrove Desa $\mathrm{Pa}$ laes.

3. Berdasarkan perhitungan INP untuk mengetahui eksistensi suatu jenis dalam suatu komunitas yang dikaji, hutan mangrove Desa Palaes didominasi oleh jenis Rhizophora sebesar 109.499. Data INP dari jenis lainnya secara berturut-turut yaitu jenis Brugiera sebesar 58.088, jenis Ceriops sebesar 57.492, jenis Xilocarpus sebesar 41.491, jenis Sonneratia sebesar 20.860 dan jenis Avicennia sebesar 12.860.

\section{Saran}

Dengan memperhatikan nilai ekonomi total yang diperoleh dari ekosistem hutan mangrove di Desa Palaes, ternyata hutan mangrove mempunyai manfaat dan fungsi yang penting sebagai semberdaya ekonomi maupun sumberdaya ekologi bagi kehidupan masyarakat yang berada disekitarnya. Oleh karena itu keberadaan (kondisi fisik) ekosistem hutan mangrove harus tetap dipelihara sebagai aset pembangunan, baik itu oleh masyarakat setempat maupun pihak lain seperti pemerintah, swasta, peneliti dan LSM, sehingga kegiatan pembangunan dapat berjalan dengan baik dan ketersediaan sumberdaya hutan mangrove tetap terjamin.

\section{DAFTAR PUSTAKA}

Adrianto L. 2005. Sinopsis Pengenalan Konsep dan Metodologi Valuasi Ekonomi Sumberdaya Pesisir dan Laut. Bogor. Pusat Kajian Sumberdaya Pesisir dan Lautan. Institut Peranian Bogor.

Anonim. 1997. Rencana Pengembangan Sumberdaya Mangrove Jilid dua Pulau Muna Barat-Laut Sulawesi Tenggara, Indonesia. Dirjen RLPS Dephut RI. Jakarta.

2007. Studi Valuasi sumber daya alam dan lingkungan di Kawasan Lindung (Konservasi), Satuan Kerja Deputi Menteri Bidang pembinaan Sarana Teknis dan Peningkatan Kapasitas Kementerian Negara Lingkungan Hidup. Jakarta.

Bengen GD. 2000. Pengenalan dan Pengelolaan Ekosistem Mangrove. Bogor. Pusat Kajian Sumberdaya Pesisir dan Lautan. Institut Pertanian Bogor.

2001. Sinopsis Ekosistem dan Sumberdaya Alam Pesisir dan Lautan. Bogor. Pusat Kajian Sumberdaya Pesisir dan Lautan. Institut Pertanian Bogor.

Budiyatno. 2002. Partisipasi Masyarakat dalam Pengelolaan Ekosistem Mangrove Pulau Kecil Berpenghuni (Studi Kasus di Pulau Lancang Besar, Kelurahan Pulau Pari, Kecamatan Pulau Seribu Selatan, Kabupaten Administrasi Kepulauan Seribu, Jakarta). [Tesis] Bogor. Program Pasca Sarjana. Institut Pertanian Bogor. 
Dwiatmojo A. Valuasi Ekonomi Wisata Alam Senggigi (NTB). http://www.scribd.com/doc/8598633/VALU ASI-EKONOMI-WISATA-ALAMSENGGIGI. [di akses 7 Desember 2009].

Fahrudin A. 1996. Analisis Ekonomi Pengelolaan Lahan Pesisir Kabupaten Subang, Jawa Barat. [Tesis]. Bogor. Program Pasca Sarjana. Institut Pertanian Bogor.

Fauzi A. 1999. Teknik Valuasi Ekonomi Mangrove. [Bahan Pelatihan]. "Management for Mangrove Forest Rehabilitation". Bogor. Institut Pertanian Bogor. 2000. Persepsi Terhadap Nilai Ekonomi Sumberdaya. [Bahan Pelatihan]. Pengelolaan Wilayah Pesisir Terpadu. Bogor. Institut Pertanian Bogor.

2006. Ekonomi Sumberdaya Alam dan Lingkungan Teori dan Aplikasi. PT. Gramedia Pustaka Utama. Jakarta.

Nybakken JW. 1998. Biologi Laut. Jakarta: Gramedia.

Pardede B, 2005. Upaya Mendukung Partisipasi Masyarakat Pesisir DalamMenunjang Rehabilitasi Hutan mangrove [Thesis). Jakarta. Program Studi Ilmu Lingkungan. Universitas Indonesia.
Ridwansyah M, 2007. Penilaian Sumberdaya Mangrove di batu Ampar, Kalimantan Barat. Jurnal Ekonomi Lingkungan.Jakarta

Santoso. 2005. Valuasi Ekonomi Ekosistem Hutan Mangrove di Kawasan Pondok Bali, Desa Legonwetan, Kecamatan Legonkulon, Kabupaten Subang, Jawa Barat. Bogor. Institut Pertanian Bogor.

Sofyan A. 2003. Valuasi Ekonomi pemanfaatan Hutan Mangrove di Desa Blanakan Kabupaten Subang, Jawa Barat. [Skripsi]. Bogor. Fakultas Perikanan dan Ilmu Kelautan. Institut Pertanian Bogor.

Talib MF, 2008. Struktur Dan Pola Zonasi (Sebaran) Mangrove Serta Makrozoobenthos Yang Berkoeksistensi, Di Desa Tanah Merah Dan Oebelo Kecil Kabupaten Kupang [Skripsi]. Bogor. Fakultas Perikanan dan Ilmu Kelautan. Institut Pertanian Bogor.

Tresnowati HS, 2003. Valuasi Ekonomi Hutan Mangrove Untuk Usaha Tambak Perikanan.[Thesis]. Jakarta. Program Studi Ilmu Lingkungan. Universitas Indonesia. 